\title{
Do Central Bank Independence Reforms Matter for Inflation Performance?*
}

\author{
Mats Landström ${ }^{\dagger}$
}

November 4, 2009

\begin{abstract}
A difference-in-difference approach was used to investigate whether Central Bank Indepencence (CBI) reforms matter for inflation, based on a novel data set including the possible occurence of such reforms in 132 countries during the period 1980-2003. CBI-reforms are found to have contributed to bringing down high inflation rates where those existed, but they seem unrelated to performance in low-inflation countries.
\end{abstract}

JEL classification: E52; E58.

Keywords: Monetary policy; institutional reforms; central banking; price stability; political economy; delegation.

${ }^{*}$ I would like to thank Sven-Olov Daunfeldt, Niklas Rudholm, Karl-Gustaf Löfgren, Jeroen Klomp, Jörgen Hellström, and Thomas Aronsson for valuable comments.

${ }^{\dagger}$ Department of Economics, Umeå University, and Department of Business Administration and Economics, University of Gävle, SE-80176 Gävle, Sweden. e-mail: mlm@hig.se Tel: $+46(0) 26648611$. 


\section{Introduction}

In recent years many countries have implemented institutional reforms that formally established the independence of central banks from elected policymakers (Daunfeldt et al., 2008). The reason for this might be that independent central banks are widely believed to perform better at achieving low inflation than central banks controlled by politicians. The theoretical background of this belief is the literature on time-inconsistency in monetery policy (Kydland and Prescott, 1977; Barro and Gordon, 1983; Rogoff, 1985).

There is some empirical evidence that countries with independent central banks have lower inflation (Cukierman, 2008). For example, Cukierman et al. (1992) and Alesina and Summers (1993) found a negative correlation between average inflation and the degree of central bank independence (CBI), suggesting that inflation might be reduced via CBI-reforms.

However, these studies used data from only a small set of mostly highly industrialized countries. Cukierman et al (2002), on the other hand, studied the relation between $\mathrm{CBI}$ and inflation in 26 former socialist countries during their transition to market economies, but found no correlation, at least in the early stages of economic liberalization. Cukierman et al (1993) also found no correlation between CBI and inflation in up to 70 less-developed countries. Thus the importance of CBI might differ across countries at different levels of development. Therefore it might be helpful to increase the number of countries under study.

In addition, previous studies have not addressed the question of endogeniety, since correlation analysis is not sufficient for establishing a causal 
relationship between variables. It might be that low inflation leads to more $\mathrm{CBI}$, rather than the other way around. Or there might have been a variable omitted from the models that caused both CBI and low inflation, for example social attitudes (Posen, 1993; Hayo, 1998). The construction of CBI indices is also somewhat subjective, potentially leading to bias (Forder, 1996, 1998; Mangano, 1998). ${ }^{1}$

This paper thus studies whether countries that implemented CBI reforms performed better in terms of inflation than those that did not, while expanding the dataset and taking into account possible endogeniety and subjectivity, during the study period, 1980-2003. Legal changes considered CBI reforms are those reforms that formally decreased the influence of elected politicians on monetary policy.

The focus is thus on changes in the legal independence of central banks, instead on the level of CBI. As all the reforms increased CBI, the subjectivity that plagues most commonly used CBI indices (Daunfeldt and de Luna, 2008) is reduced. However, focusing on changes rather than level does not totally eliminate bias as there is still some subjectivity in interpreting what constitutes a change. For example, it might be argued that a change was too small to be considered a real change, or that it was in a dimension not relevant for CBI. However, small changes are usually amendments of earlier larger changes, usually involving multiple dimensions, including CBI. ${ }^{2}$

\footnotetext{
${ }^{1}$ For example, one country might be ranked higher than another according to one criterion for CBI, but lower according to another criterion. Clearly, how the two countries are ranked according to an aggregate CBI index depends on the weights given to the two criteria. It follows that different CBI indices might rank the countries differently.

${ }^{2}$ Basically, a CBI index should be monoton and continuous in the mapping from the relevant dimensions, but it does not have meaningful cardinal interpretation. See also previous footnote.
} 
The analysis is based on a novel dataset compiled by Daunfeldt et al. (2008), covering the possible occurence of CBI reforms in 132 countries during the period 1980-2005. This means that the study includes more countries than any previous study on CBI and inflation.

The study, closely related to one by Ball and Sheridan (2005), is based on a difference-in-difference method, previously also used to identify the effect of a change in institutional (e.g., legal) factors (Meyer, 1995). Ball and Sheridan (2005) used it to study whether inflation-targeting reduced inflation in 20 OECD countries, finding that it did, but not when regression to the mean was controlled for. Instead of comparing targeters and nontargeters, countries that implemented CBI reforms during the study period are here compared to those that did not. Following Ball and Sheridan (2005), regression to the mean, the tendency of large (or small) measures to be followed by measures closer to the average ${ }^{3}$, since transitory factors tend to disappear over the long run, was controlled for by including inflation in the first year in the dataset as an explanatory variable.

In an alternative analysis, to study whether the efficiency of CBI reform depended on previous inflation rates, countries were included or excluded, depending on their level of pre-reform inflation. The difference-in-difference method eliminates endogeneity due to unobservable time-invariant countryspecific effects connected to the level of inflation. Since differences are used, these effects are cancelled out, as are any time-variant symmetric effects.

\footnotetext{
${ }^{3} \mathrm{~A}$ well-known example of this is that athletes who have been extremely successful in their rookie year in team sports, often find it almost impossible to live up to expectations during their sophomore year. More generally, an athlete's superior performance is likely to be followed by poorer performance, due to regression alone (Gilovich, 1991).
} 
Countries that implemented CBI reforms during the study period are found to have reduced inflation more than those that did not, though no such effect was found for countries with previous low inflation. The results thus seems to be driven by countries that had high pre-reform inflation, perhaps suggesting that the efficiency of CBI reform is related to recent inflation experience.

The next section presents the data and sample of countries, while section 3 presents and discusses the empirical method. Section 4 presents and discusses the results. Section 5 summarizes and draws conclusions.

\section{The Data and Descriptive Statistics}

\subsection{The data}

To investigate whether countries with CBI reforms perform better than others, dates of implementation are needed. This information is available in the dataset obtained and previously used by Daunfeldt et al. (2008).

The dates of CBI reforms were obtained by contacting, by e-mail, all central banks listed in Morgan Stanley's Central Bank Directory 2004, asking the following questions: (i) Has your country implemented any institutional reforms that grant your central bank more independence from elected policymakers? (ii) If yes, when? (iii) Where can we find more information about this?

This method of obtaining information was convenient, and had the added benefit of treating all the countries equally, at least initially, without regard 
to whether or not their central bank has posted information on a website. Of the 162 central banks contacted, 95 (59\%) answered the questionnaire. For the banks that did not, the dates of any CBI reforms were obtained from central bank acts, central bank publications, and scientific articles. These sources were also used to validate the answers obtained by e-mail.

Of interest here are reforms that established CBI in dimensions possibly relevant for inflation-bias in monetary policy, due to time-inconsistency, by naming the low inflation goal in the legislation; reducing the possibility for the government to override central bank decisions; restricting governments' opportunities to use central bank credits to finance budget deficits; reducing the power to dismiss central bank governors; increasing their terms in office and number; and so on. But, besides a clear change towards more CBI, the magnitude of change is undetermined.

The dataset consists of a panel of 132 countries over 1980-2005 (81\% of the countries that were initially contacted by e-mail), of which 89 had implemented CBI reforms during the period. The dates, as well as countries with no information on CBI reform, are presented in Daunfeldt et al. (2008), Table A1. Inflation data is missing for four countries, Afganisthan, Bosnia and Herzegovina, Georgia, and Slovak Republic, reducing the panel to 128 countries.

The countries in the dataset are classified as either reform- or non-reform countries. For countries that implemented CBI reforms, time is partitioned into pre-reform period and a post-reform periods, with the break defined as beginning of the year when the reform was implemented. To use the difference-in-difference method, a break-point between pre-reform and post- 
reform periods also needs to be defined for the countries that did not implement any CBI reforms. Following Ball and Sheridan (2005), it is defined as the unweighted average of the reform years of the reform countries. This year is 1998 , which is also the median year for reform. ${ }^{4}$ Next, average inflation was calculated for both the pre-reform and post-reform periods, for all the countries in the sample, using inflation measures from IMF Financial Statistics.

\subsection{Descriptive statistics}

The time series for median and mean inflation for reform and non-reform countries from 1980 to 2005 are presented in Figure 1 and 2, respectively. For both reform and non-reform countries, mean inflation rates were much lower during the end of the study period, as were also the median rates. Only eight countries experienced higher inflation in the post-reform period. The mean inflation rates are somewhat lower for reform countries in the post-period, compared to non-reform countries, although it was higher in the pre-reform period, giving the impression that CBI-reforms are important for improving inflation performance. Although the vertical scales are different on the two figures, the strikingly different patterns of mean and median inflation rates, may indicate problems with extreme values in the dataset, which might distort the results.

\section{- Figure 1 about here -}

\footnotetext{
${ }^{4}$ A sensitivity analysis was performed using different years depending on which economic cooperation area (e.g. EU) the countries belong to, as a break between pre- and post-reform. These analyses did not generate qualitatively different results.
} 


\section{- Figure 2 about here -}

Plotting the change in inflation against the average level of inflation in the pre-reform period (Figure 3), makes regression to the mean effect clearly visible, i.e., inflation fell more in countries that experienced higher inflation, in the pre-reform period, with no clear difference between reform and nonreform countries. The methods used for controlling for regression to the mean are discussed in the next section.

\section{- Figure 3 about here -}

Figure 3 also shows the extreme observations that can distort the results. Therefore a boxplot analysis was performed on pre-reform inflation to exclude such outliers (Figure 4). A country was considered an outlier if the pre-reform inflation was more than two standard deviation above the mean, or above $55.19 \%$. This excluded a further 23 countries, leaving 105 in the dataset.

\section{- Figure 4 about here -}

Mean and standard deviations of the variables used in the empirical analysis are presented in Table 1 . Note that the descriptive statistics supports the impression that CBI-reforms were important for reducing inflation performance. The variables are further explained in the next section.

- Table 1 about here - 


\section{Empirical Model}

To investigate whether CBI reforms improved inflation performance, we distinguish between reform and non-reform countries, with a dummy variable, using a difference-in-difference, as noted. The following regression (Model I) was first estimated, using ordinary least-squares (OLS):

$$
\pi_{i}^{\text {pre }}-\pi_{i}^{\text {post }}=\alpha_{0}+\alpha_{1} D_{i}+\epsilon_{i}
$$

where $\pi_{i}^{\text {pre }}$ is average pre-reform inflation in country $i ; \pi_{i}^{\text {post }}$ is its average post-reform inflation; $D_{i}$ is a dummy variable equal to one if country $i$ implemented CBI reform during the study period, otherwise zero; and $\epsilon$ is an error-term. The parameter $\alpha_{1}$ then measures the impact of CBI reform on inflation. The hypothesis that CBI reform did not matter can be rejected if the estimate of $\alpha_{1}$ (expected to be positive) is significantly different from zero.

However, Model I might produce biased parameter estimates, since it does not control for regression to the mean. High-inflation countries, which are likely to reduce their inflation more than other countries regardless of their monetary regime, might thus distort the results.

To control for this, Ball and Sheridan (2005) added average pre-reform inflation $\left(\pi_{i}^{\text {pre }}\right)$ as an independent (as well as dependent) variable, thereby perhaps causing endogeneity, i.e., that $\pi_{i}^{\text {pre }}$ might be correlated with the error-term (Kennedy, 2003). To reduce this possible endogeniety country $i$ 's inflation in the first year in the dataset, $\pi_{i}^{0}$, is here used instead. Model II is then: 


$$
\pi_{i}^{\text {pre }}-\pi_{i}^{\text {post }}=\alpha_{0}+\alpha_{1} D_{i}+\alpha_{2} \pi_{i}^{0}+\epsilon_{i}
$$

In this case the parameter for the CBI dummy $\left(\alpha_{1}\right)$ indicates whether CBI reform affected inflation, given first year inflation.

First year inflation $\left(\pi_{i}^{0}\right)$ might be a poor proxy for regression to the mean, however, since some countries might have been able to reduce initial high inflation already in the later years of the pre-period. To control for the effect of regression to the mean in some other way, the sample was thus split into low- and high-inflation groups, according to a criteria explained below.

First, all countries were ranked according to pre-period inflation, outliers excluded. The difference between pre- and post-reform inflation was then regressed against the reform dummy, first for only the $25 \%$ with lowest prereform inflation, $5.6 \%$ or lower. Then a corresponding regression was run for all other countries. Next, a regression was run for half the countries, those with pre-reform inflation lower than $9.8 \%$, and another regression for the rest, and so on. The equations estimated were:

$$
\begin{aligned}
& \pi_{i L}^{\text {pre }}-\pi_{i L}^{\text {post }}=\alpha_{0}+\alpha_{1} D_{i L}+\epsilon_{i} \\
& \pi_{i H}^{\text {pre }}-\pi_{i H}^{\text {post }}=\alpha_{0}+\alpha_{1} D_{i H}+\epsilon_{i}
\end{aligned}
$$

where $\pi_{i L}^{\text {pre }}-\pi_{i L}^{\text {post }}$ is the inflation difference between pre- and post-reform periods for low-inflation countries; and $\pi_{i H}^{p r e}-\pi_{i H}^{p o s t}$ is for high-inflation countries. 
The CBI dummy $D_{i}$ might itself also be endogenous, due to a timevariant country-specific effect. For example, the probability of a CBI reform might increase with pre-reform inflation (and thus with positive transitory shocks), and thus be positively correlated with the error term. If the CBI dummy is endogenous in this way, then we would expect estimators related to it to be positively biased, attributing some of the reduction of inflation due to the passing of the transitory inflation to the reform. ${ }^{5}$

\section{Results}

The aim of the empirical part of the paper was to investigate whether countries that have implemented CBI-reforms, that is countries in the dataset with a dummy value of 1 , have improved their of inflation performance relative to those countries that have not implemented such institutional reforms. The results from estimating equations (1)-(2) are presented in Table 2.

\section{- Table 2 about here -}

The null hypothesis that CBI reform did not matter for inflation performance can be rejected at all conventional significance levels in Model I. In Model II, when first year inflation is included to control for the possibility of regression to the mean, CBI reform was still statistically significant. Reform countries thus improved inflation performance on the average more than non-reform countries, supporting the belief that CBI-reforms are helpful in achieving price stability.

\footnotetext{
${ }^{5}$ Angrist and Pischke (2009) discuss problems with using standard instrumentalvariable techniques when the instrumented variable is dichotomous. No instrument highly correlated with the reform dummy was found.
} 
The results from the estimations of equations $3 \mathrm{a}$ and $3 \mathrm{~b}$, for different partitions of the data, are presented in Table 3.

\section{- Table 3 about here -}

For low-inflation countries CBI reforms seems to have had no or little influence on inflation performance. The only statistically significant effect of CBI reform is actually negative, implying that countries that did not implement CBI reforms reduced inflation more than those that did. A possible explanation is that the low-inflation group includes many countries with stable political systems that had already been able to achive low inflation earlier by other means (for a similar explanation, see Daunfeldt and de Luna, 2008). CBI reforms were, with low inflation already achieved, perhaps only adopted as part of a package of reforms aimed at transition towards a market economy or towards joining a political union. When all countries were included in the group, there was a positive significant correlation. The results then, seems to be sensitive to which countries are included in the regression.

For the high-inflation countries, the CBI dummy is positive and statistically significant at the $10 \%$ level, for all regressions. Thus, CBI reforms seems to have contributed to reducing inflation in high inflation countries, beyond the reduction due to regression to the mean. A separate regression run for the high-inflation countries excluded from the main analysis, as outliers, produced no statistically significant results, perhaps due to high variability of inflation. It also may point towards a heterogenous effect of CBI reforms, hump-shaped in pre-reform inflation. To sum up, while CBI 
reforms seems to matter for inflation performance in general, it matters little for countries that already have achieved low inflation by other means.

\section{$5 \quad$ Summary and Conclusions}

One of the most important recent macroeconomic findings is the strong negative correlation between average inflation and the degree of central bank independence (CBI) (see e.g., Cukierman et al., 1992; Alesina and Summers, 1993), which suggest that inflation might be brought down with CBI reform.

In recent years many countries have implemented such reforms. Using a difference-in-difference method (Ball and Sheridan, 2005), it was studied here whether countries that implemented CBI reform performed better in terms of inflation than countries that did not. The empirical analysis was based on a dataset covering the possible occurence of CBI reforms in 132 countries during 1980-2005.

CBI reform was found to be positively related to inflation performance, meaning that countries that implemented CBI reform brought down inflation more than countries that did not.

Countries were then ranked according to the level of pre-reform inflation, and partitioned into quartiles. The difference in inflation between the preand post-reform periods was then regressed against the reform dummy for the first quartile, as well as for the other three quartiles together; then for the lower half and the upper half; finally for the lower three quartiles as well as the upper quartile. CBI reform seem to have been more efficient in reducing inflation in countries with high previous inflation, while the 
effect was not statistically significant (or even negative) in countries with low previous inflation.

Thus, the popular view that CBI reform is important for improving a country's inflation performance, is not fully supported. The efficacy of CBI reform seems instead to depend on past inflation.

In low-inflation countries it might be that politicians' unemploymenttargets coincide with the natural rate of unemployment, eliminating any need for CBI reform. In high inflation countries, on the other hand, CBI reform might be needed in order to achieve credibility for a low-inflation rule.

The results here raise the question whether there are perhaps other conditions that, together with formal legal independence of the central bank, are important for improving inflation performance. For example, the effectiveness of CBI reform might be influenced by the level of political stability in the countries. Or, the choice of nominal inflation target might matter, perhaps together with how transparent the responsibilities and actions of the central bank are to the public. These questions might be fruitful for future research.

\section{References}

Alesina, A., Summers, L., 1993. Central bank independence and macroeconomic performance: some comparative evidence. Journal of Money, Credit and Banking 25, 151-162.

Angrist, J.D., Pischke, J-S., 2009. Mostly Harmless Econometrics. Prince- 
ton University Press, Princeton, New Jersey.

Ball, L., Sheridan, N., 2005. Does inflation targeting matter? In: Bernanke, B.S., Woodford, M. (Eds.), The Inflation-Targeting Debate. University of Chicago Press, Chicago, pp. 249-276.

Barro, R.J., Gordon, D.B., 1983. A positive theory of monetary policy in a natural rate model. Journal of Political Economy 91, 589-610 .

Cukierman, A., Webb, S.B., Neyapti, B., 1992. Measuring the independence of central banks and its effect on policy outcomes. The World Bank Economic Review 6, 353-398.

Cukierman, A., Kalaitzidakis, P., Summers, L.H., Webb, S.B., 1993. Central bank independence, Growth, investment and real rates. CarnegieRochester Conference Series on Public Policy 39, 95-140.

Cukierman, A., Miller, G.P., Neyapti, B., 2002. Central bank reform, liberalization and inflation in transition economies-an international perspective. Journal of Monetary Economics 49, 237-264.

Cukierman, A., 2008. Central bank independence and monetary policymaking institutions - Past, present and future. European Journal of Political Economy 24, 722-736.

Daunfeldt, S-O., de Luna, X., 2008. Central bank independence and price stability: evidence from OECD-countries. Oxford Economic Papers 60, $410-422$.

Daunfeldt, S-O., Hellström, J., Landström, M., 2008. Why do politicians implement central bank independence reforms? Umeå Economic Studies 
733, Department of Economics, Umeå University.

De Haan, J., Van't Hag, G-J., 1995. Variation in central bank independence across countries: some provisional empirical evidence. Public Choice 85, 335-351.

Eijffinger, S., Schaling, E., 1995. The ultimate determinants of central bank independence. Discussion Paper 5, Center for Economic Research, Tilburg University .

Eijffinger, S., De Haan, J., 1996. The political economy of central bank independence. Special Papers in International Economics 19, Department of Economics, Princeton University.

Forder, J., 1996. On the assessment and implementation of institutional remedies. Oxford Economic Papers 48, 39-51.

Forder, J., 1998. The case for an independent European Central Bank: a reassessment of evidence and sources. European Journal of Political Economy 14, 53-71.

Gilovich, T., 1991. How We Know What Isn't So: The Fallibility of Human Reason in Everyday Life. Free Press, New York, NY.

Hayo, B., 1998. Inflation culture, central bank independence and price stability. European Journal of Political Economy 14, 241-263.

Jonsson, G., 1995. Institutions and macroeconomic outcomes - the empirical evidence. Swedish Economic Policy Review 2, 181-212.

Kennedy, P. 2003. A Guide to Econometrics. The MIT Press, Massachusetts. 
Kydland, F.E., Prescott, E.C., 1977. Rules rather than discretion: the inconsistency of optimal plans. Journal of Political Economy 85, 473 - 491.

Mangano, G., 1998. Measuring central bank independence: a tale of subjectivity and of its consequences. Oxford Economic Papers 50, 468-492.

Maxfield, S., 1997. Gatekeepers of Growth: The International Political Economy of Central Banking in Developing Countries. Princeton University Press, Princeton.

Meyer, B., 1995. Natural and quasi-natural experiments in economics. Journal of Business and Economic Statistics 13, 151-62.

Morgan Stanley's Central Bank Directory, 2004. Central Banking Publications, United Kingdom.

Posen, A., 1993. Why central bank independence does not cause low inflation: there is no institutional fix for politics. In: O'Brien, R., (Ed.), Finance and the International Economy 7. Oxford University Press, Oxford.

Posen, A., 1998. Central bank independence and disinflationary credibility: a missing link? Oxford Economic Papers 50, 335-359.

Rogoff, K., 1985. The optimal degree of commitment to an intermediate monetary target. Quarterly Journal of Economics 100, 1169-1190.

Vega, M., Winkelried, D., 2005. Inflation targeting and inflation behavior: a successful story? International Journal of Central Banking 1, 153-175.

Walsh, C.E., 2008. Central bank independence. In: Durlauf, S.N., Blume, L.E. (Eds.) New Palgrave Dictionary of Economics, Palgrave Macmillan, 
New York .

Willard, L. 2006. Does Inflation Targeting Matter? A Reassessment, CEPS

Working Paper No. 120. 
Table 1: Means and standard deviations of variables

\begin{tabular}{lllllll}
\hline \hline & All & \multicolumn{3}{c}{ Reform } & \multicolumn{3}{c}{ Non-Reform } \\
Variable & Mean & s.d. & Mean & s.d. & Mean & s.d. \\
\hline Pre-reform inflation & 13.79 & 12.30 & 15.86 & 13.53 & 9.98 & 8.61 \\
Post-reform inflation & 7.75 & 16.44 & 6.95 & 6.73 & 9.29 & 26.79 \\
Inflation reduction & 6.07 & 17.93 & 8.98 & 11.80 & 0.75 & 24.98 \\
Initial Inflation & 58.4 & 237.2 & 78.7 & 289.7 & 18.7 & 30.1 \\
CBI dummy & 0.66 & 0.47 & & & & \\
Number of countries & 105 & & 71 & & 34 & \\
\hline
\end{tabular}


Table 2: Determinants of inflation performance, 1980-2005

\begin{tabular}{lcccc}
\hline \hline & \multicolumn{2}{c}{ Model I } & \multicolumn{2}{c}{ Model II } \\
\hline Variable (parameter) & Est. & t-value & Est. & t-value \\
Constant $\left(\alpha_{0}\right)$ & 0.74 & 0.26 & 0.52 & 0.18 \\
CBI dummy $\left(\alpha_{1}\right)$ & 8.24 & 2.30 & 7.54 & 2.10 \\
First-year inflation $\left(\alpha_{2}\right)$ & & & 0.01 & 1.60 \\
\hline
\end{tabular}


Table 3: Inflation reduction, due to CBI reform, for different partitions of data, 1980-2005

\begin{tabular}{lcccclll}
\hline \hline & \multicolumn{3}{c}{ Low-inflation countries } & \multicolumn{3}{c}{ High-inflation countries } \\
Inflation break point & Est. & t-value & $\mathrm{n}$ & Est. & t-value & $\mathrm{n}$ \\
\hline $5.6 \%$ (25\% of sample) & -0.39 & -0.85 & 27 & 11.17 & 2.34 & 78 \\
$9.8 \%$ (50\% of sample) & -0.91 & -1.96 & 53 & 18.11 & 2.28 & 52 \\
$17.7 \%(75 \%$ of sample) & -0.46 & -0.58 & 80 & 48.00 & 2.78 & 25 \\
\hline
\end{tabular}




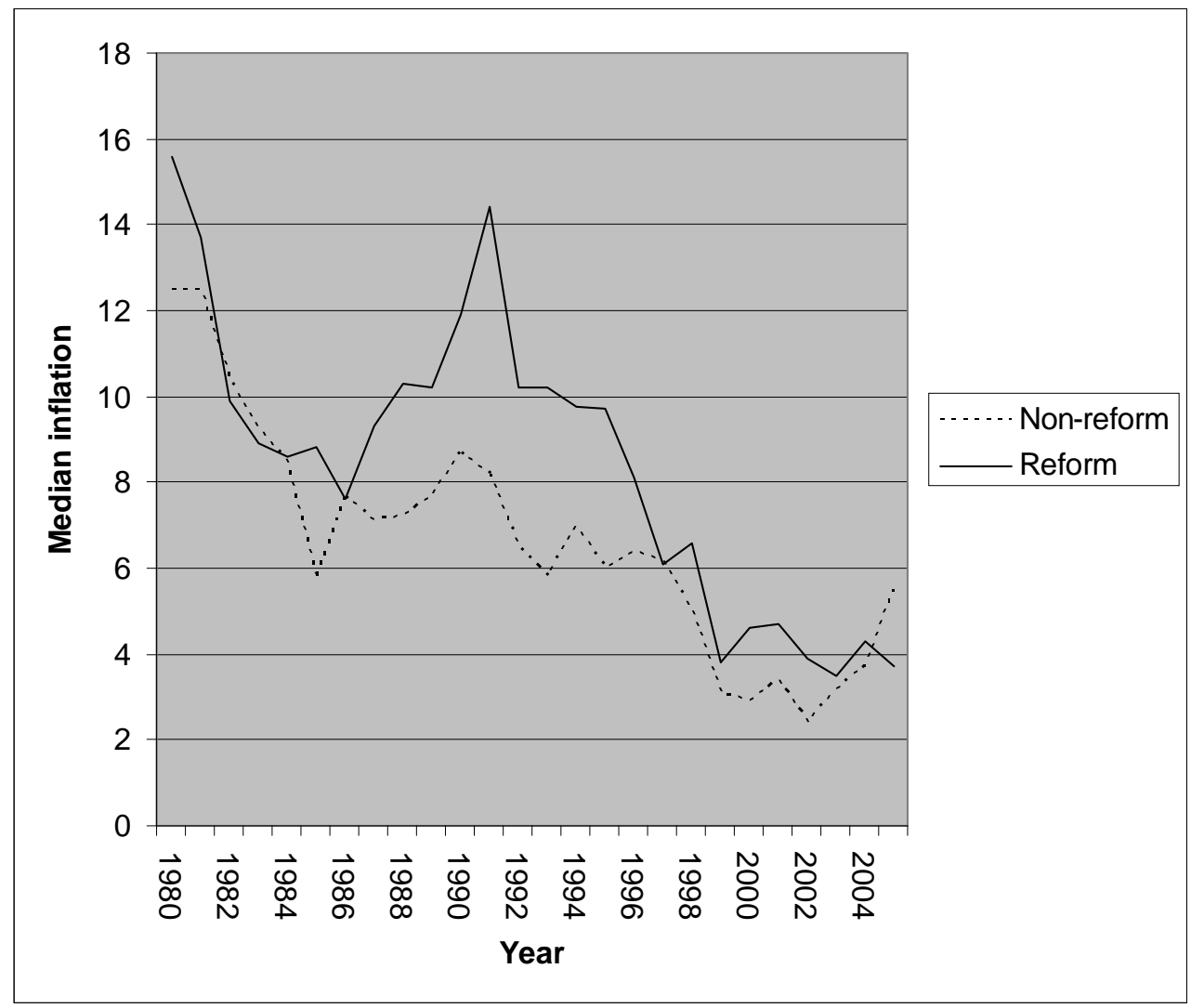

Figure 1: Median inflation in reform and non-reform countries, 1980-2005 


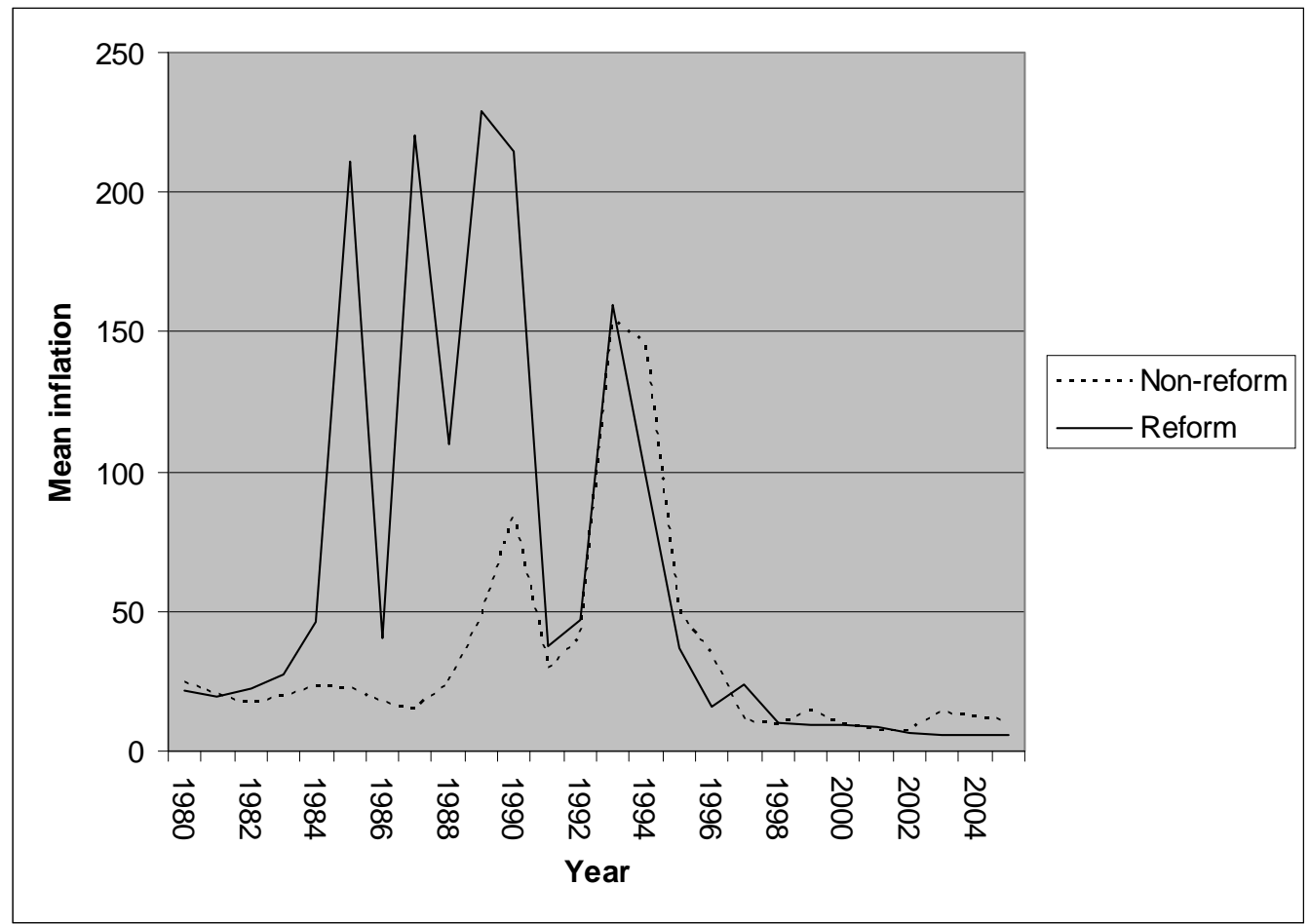

Figure 2: Mean inflation in reform and non-reform countries, 1980-2005 


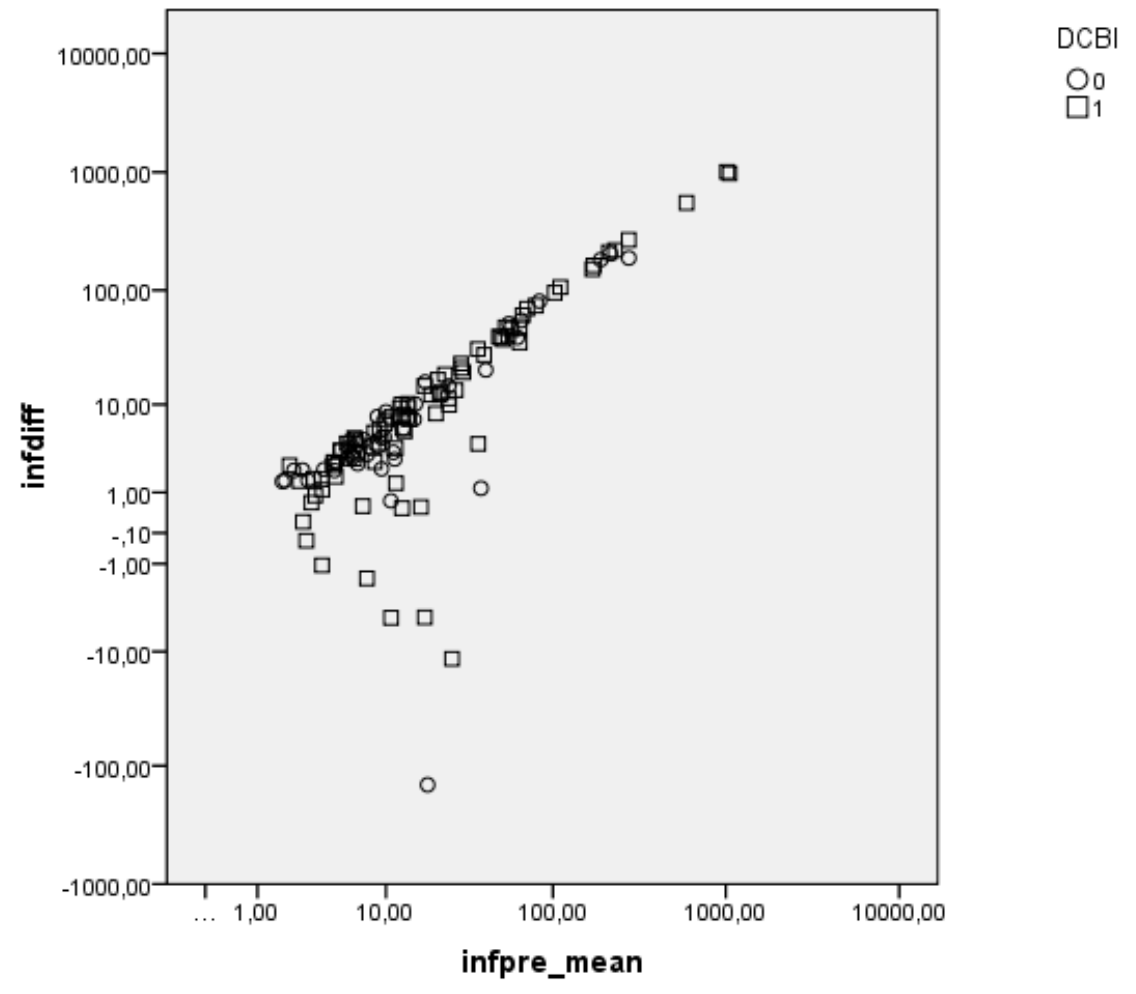

Figure 3: Change in inflation (infdiff) against the level of average inflation in the pre-reform period (infpre_mean), of reform (1) and non-reform (0) countries. 


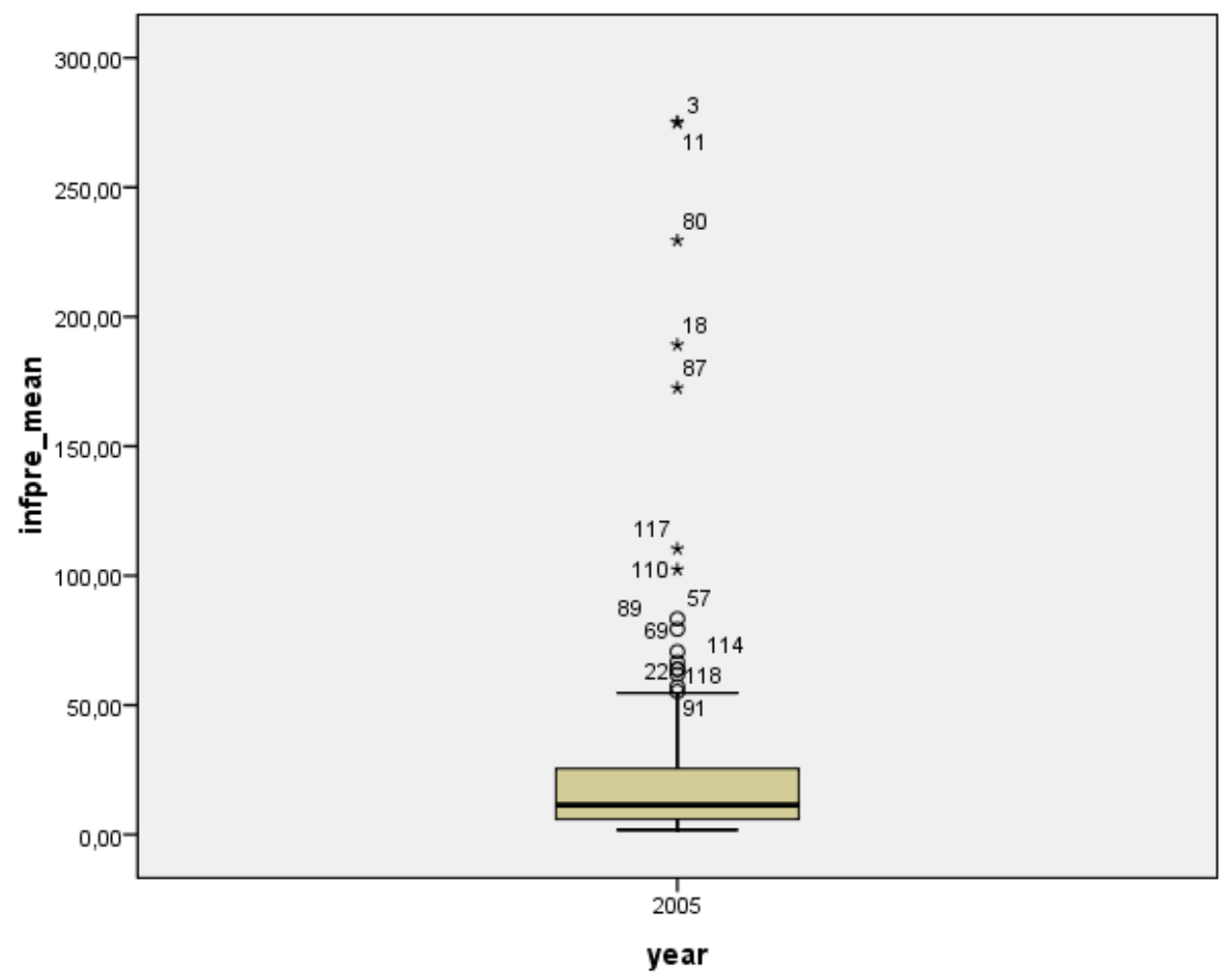

Figure 4: Boxplot of level of average inflation in the pre-reform period (infpre_mean). 